\title{
Complications of spinal osteotomy for thoracolumbar kyphosis secondary to ankylosing spondylitis in 342 patients: incidence and risk factors
}

\author{
*Bang-ping Qian, MD, Ji-chen Huang, MD, Yong Qiu, MD, Bin Wang, MD, Yang Yu, MD, \\ Ze-zhang Zhu, MD, Sai-hu Mao, MD, and Jun Jiang, MD \\ Spine Surgery, Affiliated Drum Tower Hospital, Medical School of Nanjing University, Nanjing, China
}

OBJECTIVE To describe the incidence of complications in spinal osteotomy for thoracolumbar kyphosis caused by ankylosing spondylitis (AS) and to investigate the risk factors for these complications.

METHODS From April 2000 to July 2017, 342 consecutive AS patients with a mean age $( \pm$ SD) of $35.4 \pm 9.8$ years (range 17-71 years) undergoing spinal osteotomy were enrolled. Patients with complications within the 1st postoperative year were identified. Demographic, radiological, and surgical data were compared between patients with and without complications. The complications were classified into intraoperative and postoperative complications.

RESULTS A total of 310 consecutive pedicle subtraction osteotomy (PSO) and 37 multiple Smith-Petersen osteotomy (SPO) procedures were performed in 342 patients. Overall, 47 complications were identified in 47 patients (13.7\%), including 31 intraoperative complications and 16 postoperative complications. Patients with complications were older than those without $(p=0.006)$. A significant difference was observed in preoperative global kyphosis $(G K)$, lumbar lordosis (LL), sagittal vertical axis (SVA), and the correction of these radiographic parameters between patients with and without complications $(p<0.05)$. Two-level PSO $(p=0.022)$ and an increased number of instrumented vertebrae $(p=0.019)$ were significantly associated with an increased risk of complications.

CONCLUSIONS The overall incidence of complications was 13.7\%. Age; preoperative GK, LL, and SVA; the correction of GK, LL, and SVA; 2-level PSO; and number of instrumented vertebrae were risk factors. Therefore, the potential risk of extensive surgeries with large correction and long fusion in older AS patients with severe GK should be seriously considered in surgical decision-making.

https://thejns.org/doi/abs/10.3171/2018.6.SPINE171277

KEYWORDS ankylosing spondylitis; deformity correction; spinal osteotomy; complications; incidence; risk factors

A NKYLOSING spondylitis (AS) is a chronic immunemediated inflammatory disease primarily affecting the axial skeleton and sacroiliac joint, causing progressive ossification of the spinal ligaments and facet joints and eventually contributing to rigid thoracolumbar kyphosis. ${ }^{5,28}$ Thoracolumbar kyphosis leads to a stooped, downward-looking posture, which impairs the ability to stand upright, look straight forward, and lie flat and even disturbs respiratory and digestive function due to the compression of visceral organs in severe cases. ${ }^{4,12,22,23}$ Furthermore, physical function, psychological well-being, social activities, and working ability are affected.7,24,33,35 Thus, surgical intervention is often necessary in the advanced stage of AS to restore an erect posture and to improve quality of life.

A variety of spinal osteotomies are available for the correction of thoracolumbar kyphosis secondary to AS, 16,22,30,31,36,37,40 among which multiple Smith-Petersen osteotomies (SPOs) and pedicle subtraction osteotomy (PSO) are reported to be the 2 main options. ${ }^{22,30,36,40} \mathrm{Sev}$ eral studies have shown acceptable and good radiological and clinical outcomes after the aforementioned 2 techniques. ${ }^{2,14,15,22}$ However, the surgical and general complications following spinal osteotomy should not be ig-

ABBREVIATIONS AS = ankylosing spondylitis; GK = global kyphosis; $\mathrm{LL}=$ lumbar lordosis; $\mathrm{MEP}=$ motor evoked potential; $\mathrm{PJA}=$ proximal junctional angle; $\mathrm{PJK}=$ proximal junctional kyphosis; PSO = pedicle subtraction osteotomy; SPO = Smith-Petersen osteotomy; SSEP = somatosensory evoked potential; SVA = sagittal vertical axis;

THA $=$ total hip arthroplasty.

SUBMITTED November 28, 2017. ACCEPTED June 6, 2018.

INCLUDE WHEN CITING Published online October 12, 2018; DOI: 10.3171/2018.6.SPINE171277.

${ }^{*}$ B.P.Q. and J.C.H. contributed equally to this work. 
nored. ${ }^{2,27,39}$ To the best of our knowledge, only 1 published study in the English literature has specifically investigated the complications related to corrective osteotomy for AS patients. ${ }^{39}$ Willems et al. ${ }^{39}$ reviewed 106 cases involving AS patients who had undergone spinal osteotomies and reported a high incidence of serious complications $(7.8 \%$ permanent neurological deficit, 9.6\% deep wound infections, and $10.4 \%$ major general complications) during the 1st postoperative year. Nevertheless, the risk factors for complications were not investigated in that study. Moreover, with the considerable improvements in perioperative medical management and advances in anesthetic and surgical techniques over the past several years, the incidence of complications may have changed. The present study aimed to specifically evaluate the incidence of complications and risk factors in a large case series of AS patients undergoing spinal osteotomy (PSO and SPOs) for thoracolumbar kyphosis.

\section{Methods \\ Patient Population}

After obtaining the approval of our institutional review board, a review of prospectively collected demographic, radiographic, and surgical outcome data from our database for AS was conducted. From April 2000 to July 2017, 342 consecutive AS patients satisfying the Modified New York Criteria ${ }^{34}$ who underwent spinal osteotomy (PSO, $\mathrm{n}=305$; SPOs, $\mathrm{n}=37$ ) at our institution for correction of thoracolumbar kyphosis were identified. The present study focused on complications occurring within 1 year after surgery. Of the 342 patients, 319 patients were followed for at least 1 year. The other 23 patients were followed for less than 1 year because the period between the date of surgery and the submission date of the present paper was less than 1 year.

Preoperative data, including history of prior surgery, history of prior total hip arthroplasty (THA), and comorbidities, were reviewed. Twenty-two patients (6.4\%) had a history of prior surgery, including 14 patients with a history of prior THA (4.1\%). There were 21 patients (6.1\%) with comorbidities. Of these 21 patients, 1 patient presented with 3 kinds of comorbidities, including cholecystolithiasis, renal calculus, and hepatic cyst; 3 patients presented with 2 kinds of comorbidities; and 17 patients had 1 type of comorbidity, including hypertension in 3 patients, chronic hepatitis in 2 patients, anemia in 2 patients, congenital deformity in 2 patients (one with a lumbar hemivertebra, another with a horseshoe kidney), and diabetes, cholecystolithiasis, cervical spinal stenosis, hysteromyoma, syringomyelia, lumbar spondylolisthesis, old pulmonary tuberculosis, and rheumatoid arthritis each in 1 patient.

Operative data, including the instrumented fusion level (fusion to sacrum or not), type of osteotomy, osteotomized level, number of osteotomies, number of instrumented vertebrae, and blood loss in each procedure, were also recorded.

\section{Radiographic Evaluations}

Long-cassette standing lateral radiographs of the spine taken preoperatively and postoperatively were obtained. Global kyphosis (GK) was defined as the angle between the upper endplate of the maximally tilted upper end vertebra and the lower endplate of the maximally tilted lower end vertebra. ${ }^{28}$ Lumbar lordosis (LL) was measured between the superior endplate of T12 and S1. For GK and LL, a positive value indicated kyphosis. ${ }^{28}$ The sagittal vertical axis (SVA) was defined as the distance between the $\mathrm{C} 7$ plumb line and the posterosuperior corner of $\mathrm{S} 1{ }^{28}$ The SVA was positive if the C7 plumb line was anterior to the posterosuperior corner of S1. ${ }^{28} \mathrm{GK}, \mathrm{LL}$, and SVA were measured in both preoperative and postoperative radiographs to calculate the postoperative correction. The existence of preoperative pseudarthrosis was determined by any of the following findings: $:^{18,28} 1$ ) a widened disc space and irregular vertebral endplates with surrounding sclerosis in anteroposterior and lateral radiographs; 2) irregular discovertebral osteolysis with reactive sclerosis, vacuum phenomenon, or lamina fracture on CT; or 3) irregular, decreased signal intensity of the intervertebral disc on T1-weighted MRI and irregular mixture of increased, isointense, and decreased signals of the intervertebral disc on T2-weighted MRI. Vertebral subluxation at the osteotomy site was defined as anterior or posterior translation of more than $5 \mathrm{~mm}$ between the posterior inferior edge of the craniad vertebra and the posterior superior edge of the caudad vertebra at the osteotomized level on lateral radiographs. ${ }^{27}$ The proximal junctional angle (PJA) was the angle between the inferior endplate of the uppermost instrumented vertebra (UIV) and the superior endplate of the 2 vertebrae above. ${ }^{13}$ Radiographic proximal junctional kyphosis (PJK) was defined by both of the following criteria: $:^{13}$ 1) PJA $>10^{\circ}$ and 2) PJA at least $10^{\circ}$ greater than the preoperative measurement.

\section{Surgical Procedures}

The indications for the corrective osteotomy were 1) inability to stand upright and look straight forward without flexion of hips and/or knees; 2) inability to lie down flat with the head touching the pillow; 3) severe limitations in daily activities such as walking, driving, and interpersonal communication due to impairment in horizontal gaze caused by thoracolumbar kyphosis; and 4) severe indigestion due to the compression of the abdominal visceral organs secondary to thoracolumbar kyphosis. ${ }^{8,24}$

Under general anesthesia, the patient was placed prone on a special bow-type frame that was solidly attached to the operating table and allowed both accommodation of the kyphotic spine and correction of the kyphosis simultaneously after the osteotomies. A standard midline incision was performed with dissection laterally to the transverse process to expose the posterior elements of the spine. ${ }^{26}$ Pedicle screws were inserted into the planned vertebrae.

The indications for SPOs were 1) young patient age without ossification of the anterior longitudinal ligaments and 2) absence of osteoporosis (to ensure no collapse in the middle column of the vertebral body during the corrective procedures). ${ }^{8}$ After excising the spinous processes, a 7- to $10-\mathrm{mm}$ posterior chevron-shaped osteotomy was performed with bilateral resection of the interlaminar space, ligamentum flavum, and superior and inferior ar- 
ticular processes. The spine was hinged at the posterior annulus fibrosis, opened anteriorly at the still mobile disc space, and shortened posteriorly. ${ }^{36}$

A PSO was indicated for the patients with ossification of the anterior longitudinal ligaments, significant aortic atherosclerosis, or osteoporosis. ${ }^{8}$ Two-level PSO was indicated for patients with severe global kyphosis $(\mathrm{GK} \geq$ $90^{\circ}$ ) requiring more than $60^{\circ}$ of correction to achieve a satisfactory postoperative sagittal alignment. The PSO involved complete removal of the posterior elements, including the laminae, pedicles, and transverse processes, and a partial corporectomy. When gradually straightening the bow-type frame, the correction of kyphosis was achieved by closing the osteotomy gap, with the anterior cortex acting as a hinge. ${ }^{8}$ To achieve a substantial kyphosis correction, the PSO procedure was usually performed in the apical region of the kyphosis.

All the procedures were performed under continuous monitoring of both somatosensory and motor evoked potentials (SSEPs and MEPs). In addition, a wake-up test was performed after closure of the osteotomy site in all patients.

\section{Complications}

Complications were stratified into intraoperative and postoperative (within 1 year postsurgery) and further stratified into surgical, anesthesia, and general categories, as shown in Table 1. This classification system was based on the classifications of complications used by Willems et al. ${ }^{39}$ and Auerbach et al. ${ }^{3}$ In the present study, intraoperative nerve root injury, motor deficits (without full recovery before discharge), inadvertent extubation, acute pulmonary edema, acute pancreatitis, duodenal perforation, wound dehiscence, and any complication that required revision surgery were defined as major complications.

\section{Statistical Analysis}

Descriptive data were presented as mean and standard deviation for continuous variables and as frequencies and percentages for categorical variables. An independent Student t-test was performed to compare the continuous variables. Categorical variables were compared using the chi-square or Fisher's exact test as appropriate. The p value calculated from the Fisher's exact test was used when at least 1 cell had an expected count of less than 5. All statistical analyses were performed using SPSS 19 (IBM Corp.). A value of $\mathrm{p}<0.05$ was considered to be statistically significant.

\section{Results \\ Patient Data}

A total of 342 AS patients (306 male and 36 female) with a mean age $( \pm \mathrm{SD})$ of $35.4 \pm 9.8$ years (range 17-71 years) underwent 347 operations. Thirty-seven patients received SPOs involving 4 to 5 levels (mean 4.4 levels), and the osteotomy sites were located at T10-L3 in 2 cases, T11-L4 in 9 cases, T12-L4 in 23 cases, and T12-L5 in 3 cases. The mean number of instrumented fusion levels was 5.4 (range 5-6). The mean estimated blood loss was $960 \mathrm{~mL}$ (range 600-2000 mL).

Three hundred five patients underwent PSO, with
TABLE 1. Classification of all complications of spinal osteotomy observed in the AS patients with thoracolumbar kyphosis in this study

\begin{tabular}{|c|c|c|}
\hline Category & Intraop Complications & Postop Complications* \\
\hline Surgical & $\begin{array}{l}\text { Vertebral subluxation } \\
\text { Nerve root injury } \\
\text { Dural tears }\end{array}$ & $\begin{array}{l}\text { Neurological complications: } \\
\text { motor deficit radiculopathy } \\
\text { Wound dehiscence } \\
\text { Mechanical complications: PJK }\end{array}$ \\
\hline Anesthesia & $\begin{array}{l}\text { Inadvertent extubation } \\
\text { Acute pulmonary edema } \\
\quad\left(\mathrm{CO}_{2} \text { narcosis }\right)\end{array}$ & \\
\hline General & $\begin{array}{l}\text { Postural brachial plexus } \\
\text { palsy }\end{array}$ & $\begin{array}{l}\text { Pleural effusion } \\
\text { Transient delirium } \\
\text { Biliogenic acute pancreatitis } \\
\text { Duodenal perforation }\end{array}$ \\
\hline
\end{tabular}

* Within 1 year of surgery.

1-level osteotomy performed in 275 cases and 2-level osteotomy in 30 cases, including 5 cases in which a staged 2-level osteotomy was performed. A 1-level osteotomy was performed at T12 in 5 cases, L1 in 53 cases, L2 in 169 cases, L3 in 46 cases, and L4 in 2 cases. The instrumented fusion levels involved 4 to 13 segments, with an average of 8.0 segments. The mean estimated blood loss was 1930 $\mathrm{mL}$ (range 500-4000 $\mathrm{mL}$ ).

A 2-level osteotomy was performed at T12 and L3 in 3 cases, L1 and L 3 in 2 cases, L1 and L4 in 13 cases, L2 and L4 in 3 cases, and L2 and L5 in 9 cases. The mean number of instrumented vertebrae was 11.3 (range 9-13) and the mean estimated blood loss was $3000 \mathrm{~mL}$ (range 1000$6500 \mathrm{~mL}$ ). Freehand technique without $\mathrm{O}$-arm navigation or intraoperative CT scan was used for screw placement.

\section{Complications}

Forty-seven complications were identified in 47 patients (13.7\%); 31 (9.1\%) of the complications were intraoperative and $16(4.7 \%)$ were early postoperative complications (Table 2). Although there were 9 major complications (2.6\%), no deaths were observed either preoperatively or postoperatively (Table 3 ).

\section{Intraoperative Complications}

One major surgical complication $(0.3 \%)$ occurred intraoperatively (a right L2 nerve root was injured during placement of the pedicle screw). Although successful reinsertion of the pedicle screw was immediately performed under intraoperative fluoroscopy, the patient presented with weakness and numbness of the right lower limb postoperatively; the symptoms resolved partially before discharge.

Despite the performance of reduction maneuvers, 10 PSO procedures (2.9\%) were complicated by subluxation of osteotomized vertebrae. The vertebral subluxations were all confirmed through intraoperative fluoroscopy. Four were due to early fracture of the anterior cortex of the osteotomized vertebra, 2 were caused by excessive transpedicular decancellation, 2 were due to insufficient decancellation of the osteotomized vertebra, and anoth- 
TABLE 2. Overview of the complications encountered in this study

\begin{tabular}{lc}
\hline \multicolumn{1}{c}{ Complications } & No. of Cases $(\%)$ \\
\hline Total & $47(13.7)$ \\
\hline Intraop (31 cases, 9.1\%) & \\
\hline Surgical complications & $11(3.2)$ \\
\hline Dural tear & $10(2.9)$ \\
\hline Vertebral subluxation & $7(2.0)$ \\
\hline Postural brachial plexus palsy & $1(0.3)$ \\
\hline Nerve root injury & $1(0.3)$ \\
\hline Anesthesia complications & $1(0.3)$ \\
\hline Inadvertent extubation & \\
\hline Acute pulmonary edema $\left(\mathrm{CO}_{2}\right.$ narcosis) & $3(0.9)$ \\
\hline Postop, w/in 1 yr (16 cases, $4.7 \%)$ & $6(1.8)$ \\
\hline Surgical complications & $1(0.3)$ \\
\hline Motor deficit & $1(0.3)$ \\
\hline Radiculopathy & \\
\hline Wound dehiscence & $2(0.6)$ \\
\hline PJK & $1(0.3)$ \\
\hline General complications & $1(0.3)$ \\
\hline Pleural effusion & $1(0.3)$ \\
\hline Transient delirium &
\end{tabular}

er 2 were caused by improper application of a cantilever technique with long instrumentation. Fortunately, no patient with intraoperative vertebral subluxation presented with neurological complications.

Due to dural adhesions with the ossified ligamentum flavum, intraoperative dural tears occurred in 11 cases $(3.2 \%)$. In 4 cases, the dura was sutured, and in the other 7 cases, a gelatin sponge was placed on it. Six patients experienced cerebrospinal fluid leakage after surgery, but without neurological complications or infection.
Due to the position of patients during the spinal osteotomy, 7 patients $(2.0 \%)$ had complications of brachial plexus palsy, which mainly manifested as pain and weakness of the upper limb. Neurological function had been completely recovered through active functional exercises by the 6-week follow-up evaluation.

Two major anesthesia complications $(0.6 \%)$ occurred intraoperatively. One patient presented with acute pulmonary edema and $\mathrm{CO}_{2}$ narcosis $\left(\mathrm{PaCO}_{2} 105 \mathrm{~mm} \mathrm{Hg}\right)$. After being transferred to an intensive care unit immediately after surgery, the patient received treatment for acidosis and pulmonary edema. The patient required prolonged hospitalization but recovered fully. In another case inadvertent extubation occurred during reduction of the osteotomy site. The surgery was immediately stopped and the patient was turned over and reintubated. Fortunately, no serious consequences occurred (Table 2).

\section{Postoperative Complications (Within 1 Year After Surgery)}

There were 11 complications $(3.2 \%)$ directly related to the surgery. Nine neurological problems (2.6\%) were identified, including motor deficits in 3 cases $(0.9 \%)$ and radiculopathies in 6 cases $(1.8 \%)$. In one of the 3 cases of motor deficits, the complication was identified through the intraoperative disappearance of SSEP and MEP during the closure of the osteotomy at the pseudarthrosis level of T12. Extensive decompression with laminectomy was immediately performed, and the closed osteotomy site was partially loosened to decrease the correction of kyphosis. Postoperatively, the patient presented with weakness of the lower limbs (grade 2/5), and 2 weeks later the muscle strength had recovered to grade $3 / 5$. Another patient also underwent PSO through pseudarthrosis. While the intraoperative monitoring and neurological functions immediately after surgery were normal, the patient developed weakness (grade 3/5) and numbness of the lower limbs the next day. An urgent enlarged decompression of the osteotomy site was performed. Slight improvement of muscle strength to grade $4 / 5$ was observed before discharge. The other patient, who had normal neurological status immediately after surgery, presented with motor dysfunction of the lower

TABLE 3. Major complications with their treatment and extent of recovery

\begin{tabular}{|c|c|c|c|c|c|c|}
\hline Case No. & Age (yrs), Sex & Major Complications & Osteotomy & Days Postop & Treatment & Recovery \\
\hline 1 & $45, \mathrm{~F}$ & $\begin{array}{l}\text { Acute pulmonary edema } \\
\text { (intraop } \mathrm{CO}_{2} \text { narcosis) }\end{array}$ & L2, L4 PSO & During op & $\begin{array}{l}\text { Assisted ventilation/acidosis } \\
\text { correction/ABx }\end{array}$ & Full recovery \\
\hline 2 & $44, \mathrm{M}$ & $\begin{array}{l}\text { Biliogenic acute pancre- } \\
\text { atitis }\end{array}$ & L2 PSO & 18 & $\begin{array}{l}\text { Fasting/GI decompression/ABx/ } \\
\text { fluid infusion }\end{array}$ & Full recovery \\
\hline 3 & $43, \mathrm{M}$ & LE motor deficit & L2 PSO & 3 & Drug Tx/functional exercise & Partial recovery \\
\hline 4 & $46, \mathrm{M}$ & LE motor deficit & L1 PSO & 2 & $\begin{array}{l}\text { T12-L2 decompression/drug } \\
\text { Tx/functional exercise }\end{array}$ & Partial recovery \\
\hline 5 & $40, M$ & LE motor deficit & T12 PSO & Immediately after op & Drug Tx/functional exercise & Partial recovery \\
\hline 6 & $30, F$ & L2 nerve root injury & L1 PSO & During op & Drug Tx/functional exercise & Partial recovery \\
\hline 7 & $23, \mathrm{M}$ & Inadvertent extubation & L2 PSO & During op & Reintubation & Full recovery \\
\hline 8 & $41, \mathrm{M}$ & Duodenal perforation & L1 PSO & 3 & Urgent exploratory laparotomy & Full recovery \\
\hline 9 & $23, \mathrm{~F}$ & Wound dehiscence & L1 PSO & 10 & Dressing change/drainage & Full recovery \\
\hline
\end{tabular}

$\mathrm{ABx}=$ antibiotic(s); $\mathrm{GI}=$ gastrointestinal; $\mathrm{LE}=$ lower extremity; $\mathrm{Tx}=$ therapy. 
TABLE 4. Comparison of demographic, radiographic, and surgical variables between patients with and without complications

\begin{tabular}{|c|c|c|c|c|}
\hline Variable & Pts w/o Periop Comps $(n=295)$ & Pts w/ Periop Comps $(n=47)$ & OR $(95 \% \mathrm{Cl})$ & p Value \\
\hline Age (yrs), mean & $34.8 \pm 9.8$ & $39.1 \pm 9.5$ & & 0.006 \\
\hline \multicolumn{5}{|l|}{ Sex } \\
\hline Female & $27(9.2 \%)$ & $9(19.1 \%)$ & $2.4(1.0-5.4)$ & 0.068 \\
\hline Male & $268(90.8 \%)$ & $38(80.9 \%)$ & & \\
\hline Preop pseudarthrosis $(n=62)$ & $50(16.9 \%)$ & $12(25.5 \%)$ & $1.7(0.8-3.5)$ & 0.156 \\
\hline History of prior op $(n=22)$ & $18(6.1 \%)$ & $4(8.5 \%)$ & $1.4(0.5-4.4)$ & 0.522 \\
\hline History of prior THA $(n=14)$ & $12(4.1 \%)$ & $2(4.3 \%)$ & $1.0(0.2-4.7)$ & 1.000 \\
\hline Comorbidity $(n=21)$ & $18(6.1 \%)$ & $3(6.4 \%)$ & $1.0(0.3-3.7)$ & 1.000 \\
\hline Preop GK $\left({ }^{\circ}\right)$, mean & $72.0 \pm 20.7$ & $79.2 \pm 22.3$ & & 0.029 \\
\hline Preop LL $\left({ }^{\circ}\right)$, mean & $-2.3 \pm 18.2$ & $6.7 \pm 19.1$ & & 0.003 \\
\hline Preop SVA (mm), mean & $170.0 \pm 68.2$ & $205.9 \pm 77.4$ & & 0.007 \\
\hline Postop correction of GK $\left(^{\circ}\right)$, mean & $41.0 \pm 12.7$ & $46.6 \pm 17.0$ & & 0.037 \\
\hline Postop correction of LL $\left({ }^{\circ}\right)$, mean & $39.9 \pm 14.2$ & $46.6 \pm 17.2$ & & 0.025 \\
\hline Postop correction of SVA (mm), mean & $104.5 \pm 70.8$ & $136.9 \pm 71.6$ & & 0.027 \\
\hline \multicolumn{5}{|l|}{ Type of osteotomy } \\
\hline PSO & $262(88.9 \%)$ & $43(91.5 \%)$ & $1.4(0.5-4.0)$ & 0.583 \\
\hline SPO & $33(11.2 \%)$ & $4(8.5 \%)$ & & \\
\hline \multicolumn{5}{|l|}{ No. of PSO levels $(n=305)(\%$ in PSO) } \\
\hline 2 & $21(8.0 \%)$ & $9(20.9 \%)$ & $3.0(1.3-7.2)$ & 0.022 \\
\hline 1 & $241(92.0 \%)$ & $34(79.1 \%)$ & & \\
\hline No. of instrumented vertebrae, mean & $7.9 \pm 2.2$ & $8.7 \pm 2.0$ & & 0.019 \\
\hline Fusion to sacrum $(n=64)$ & $55(18.6 \%)$ & $9(19.1 \%)$ & $1.0(0.5-2.3)$ & 0.934 \\
\hline
\end{tabular}

Comps = complications.

Data are presented as numbers of patients (\%) unless otherwise indicated. Mean values are presented with standard deviations. Boldface type indicates statistical significance.

limbs (grade 3/5) 3 days postoperatively for unknown reasons and obtained partial recovery of muscle strength to grade $4 / 5$ after 2 weeks of functional exercises. Six patients $(1.8 \%)$ had postoperative radiculopathy with lower limb numbness, and they recovered fully before discharge. One female patient $(0.3 \%)$ experienced wound dehiscence 10 days after surgery. After careful daily dressing changes and persistent drainage, the wound was completely healed 3 weeks postoperatively. One patient $(0.3 \%)$ developed a mechanical complication within 1 year. This patient presented with a radiographic PJK (PJA $13^{\circ}$ ) at 8 months' follow-up. She was asymptomatic, without obvious back pain, and did not require revision surgery. At the 2-year follow-up visit, no substantial progression was observed (PJA $18^{\circ}$ ).

Five patients $(1.5 \%)$ presented with general complications after surgery. Pleural effusion occurred in 2 patients $(0.6 \%)$ due to intraoperative injury to the pleura, and in both cases it was treated successfully with thoracic closed drainage. One patient $(0.3 \%)$ presented with delirium 2 days after surgery. The symptom disappeared following the administration of antipsychotic drugs. Two patients $(0.6 \%)$ exhibited major digestive complications. One of them complained about severe abdominal pain 3 days after surgery, and free gas under the diaphragm was observed on an abdominal plain radiograph. An urgent exploratory laparotomy was performed to repair a perforated duodenum, and the patient's symptoms gradually improved after surgery. Another patient was diagnosed with biliogenic acute pancreatitis 18 days after surgery. The condition was treated with fasting, gastrointestinal decompression, antibiotics, and fluid infusion, and the patient appeared to have fully recovered 2 weeks later (Table 2).

\section{Risk Factors for Complications}

\section{Demographic Risk Factors}

Patients with complications were older than those without complications $(\mathrm{p}=0.006)$. Although the proportion of females in the group with complications was larger than that in the group without complications, the difference was not statistically significant $(p=0.068)$. There was a trend toward patients with preoperative pseudarthrosis being more likely to experience complications, but the difference was not significant $(p=0.156)$. The distribution of other preoperative status variables, including history of prior surgery, history of prior THA, and comorbidity, was similar between the 2 groups $(p>0.05)$ (Table 4$)$.

\section{Radiographic Risk Factors}

There was a significant difference in preoperative GK, LL, and SVA between patients with and without complications ( $p=0.029,0.003$, and 0.007 , respectively). A significant difference was also observed in the correction of GK in these 2 groups $(p=0.037)$. In addition, patients with complications had more correction of the LL $(p=0.025)$ and SVA $(\mathrm{p}=0.027)($ Table 4). 


\section{Surgical Risk Factors}

Patients who underwent 2-level PSO (OR 3.0, 95\% CI $1.3-7.2, p=0.022$ ) were found to have an increased likelihood of complications compared with those who underwent a 1-level PSO. Interestingly, compared with SPOs, PSOs did not increase the risk of complications, regardless of the number of osteotomies in each procedure $(\mathrm{p}=$ 0.583 ). The number of instrumented vertebrae was significantly greater in patients with complications $(p=0.019)$. However, fusion to the sacrum was not associated with an increased likelihood of complications (OR 1.0, 95\% CI $0.5-2.3, p=0.934)$ (Table 4).

\section{Radiological Outcome}

The mean correction of GK, LL, and SVA in SPOs was $36.3^{\circ}\left(\right.$ range $\left.19-63^{\circ}\right), 30.5^{\circ}\left(\right.$ range $5^{\circ}-65^{\circ}$ ), and 125.8 $\mathrm{mm}$ (range $25-181 \mathrm{~mm}$ ), respectively. In patients treated with 1-level PSOs, the mean correction of GK, LL, and SVA was $39.0^{\circ}$ (range $\left.10^{\circ}-70^{\circ}\right), 39.6^{\circ}$ (range $6^{\circ}-63^{\circ}$ ), and $115.9 \mathrm{~mm}$ (range $2-323 \mathrm{~mm}$ ), respectively, while an improvement in GK, LL, and SVA of $60.6^{\circ}$ (range $45^{\circ}-84^{\circ}$ ), $56.0^{\circ}$ (range $3^{\circ}-87^{\circ}$ ), and $166.8 \mathrm{~mm}$ (range $2-275 \mathrm{~mm}$ ) was observed in patients treated with 2-level PSOs, respectively.

\section{Discussion}

In 1945, SPO was first reported by Smith-Petersen et al. for the correction of thoracolumbar kyphosis secondary to AS. ${ }^{31}$ This type of osteotomy allowed considerable correction of kyphotic deformity by forceful manual extension of the lumbar spine to close the posterior wedge osteotomies. However, this manipulation creates a sharp anterior monosegmental intervertebral wedge with elongation of the anterior column that may lead to serious vascular and neurological complications..$^{1,21,38}$ To avoid such complications, polysegmental wedge osteotomies (multiple SPOs) and a closing wedge osteotomy (PSO) were introduced. First described by Wilson and Turkell, ${ }^{40}$ multiple SPOs provided a more gradual correction without rupturing the anterior longitudinal ligament and created a harmonious lumbar lordosis. PSO, which was first performed by Scudese and Calabro in $1963,{ }^{30}$ is currently one of the standard techniques for the correction of kyphosis secondary to AS. Nevertheless, complications following multiple SPOs or PSO for thoracolumbar kyphosis caused by AS are not uncommon. The current study aimed to report the incidence of complications and investigate the related risk factors in spinal osteotomy (PSO and multiple SPOs) for the correction of thoracolumbar kyphosis caused by AS.

The overall complication incidence in the present series was $13.7 \%$ (47/342), which was relatively lower than that reported by Chang et al., ${ }^{8}$ who studied 117 cases involving AS patients undergoing corrective surgery for kyphotic deformity and reported a $37.6 \%$ incidence of complications during a minimum 2-year follow-up after surgery. The relatively short observation time for complications in the present study may be one possible explanation for the relatively low complication rates in the current study.

Surgical neurological complications could include motor or sensory deficits, radiculopathy or myelopathy, bowel or bladder dysfunction, and epidural hematomas. ${ }^{17}$ In this study, 17 surgical neurological complications occurred, with a rate of $5.0 \%$. Of the 17 patients, 6 presented with transient postoperative radiculopathy. However, 3 patients experienced severe motor deficits. The possible causes, including residual dorsal impingement, dural buckling, and spinal cord ischemia, reported in the published literature may be responsible for these complications. ${ }^{6}$ In the present study, 7 patients presented with postural brachial plexus palsy, and the reported incidence in this study $(2.0 \%)$ was comparable to that in previous studies reporting postural brachial plexus palsy in scoliosis surgery (3.6\% by Schwartz et al. ${ }^{29}$ and $6.2 \%$ by Labrom et al. ${ }^{20}$ ). A literature review suggested that patient malpositioning during surgery (especially in a prone position with arms abducted greater than $90^{\circ}$ ) is the main determining factor for the development of postoperative brachial plexus injury. ${ }^{32}$ Intraoperative SSEP monitoring has been shown to be beneficial in the early detection of brachial plexopathy. ${ }^{20,29}$ Therefore, special attention to the patient's position, careful assessment of neurological function via MEP and SSEP signals after patient positioning, and continuous monitoring of MEP and SSEP during surgery are essential for the prevention of postural brachial plexus palsy.

Other surgical complications encountered in our cohort included vertebral subluxation, dura tears, and wound dehiscence. Vertebral subluxation typically occurs at the osteotomy site during the PSO procedure, which is a 3-column osteotomy with unrestricted movement of the hinge on the anterior column. Vertebral subluxation may be more common in AS patients due to the ankylosed and osteoporotic spine. In our study, the overall incidence of intraoperative vertebral subluxation was $2.9 \%$ (10/342), and among the 305 patients who underwent PSO, the incidence was $3.3 \%$ (10/305). Fortunately, no patient experienced a postoperative neurological deficit due to vertebral subluxation in this study. As Qian et al. ${ }^{27}$ recommended, special attention should be paid to avoid over-decancellation of the osteomized vertebra to prevent vertebral subluxation and thereby reduce the potential risk of neurological compromise. Dura tears were not uncommon during osteotomy due to the thin dura with close adhesion to the ossified ligamentum flavum. Willems et al. ${ }^{39}$ reported a high incidence of dura tears of up to $15.7 \%$ during corrective surgery for kyphosis caused by AS. The $3.2 \%$ rate of dura tears in this study was more comparable to the published results by Cho et al. ${ }^{10}$ and Chang et al., ${ }^{8}$ which revealed a $5.6 \%$ and $6.0 \%$ incidence of dura tears in spinal osteotomy for AS, respectively. Fortunately, only 1 superficial infection with wound dehiscence was observed in the present case series. Excellent perioperative management, including prophylactic antibiotic usage, strict application of principles of asepsis in the operating room, improved intraoperative anesthetic care, and careful postoperative nursing, contributed to the relatively low infection rate.

The potential risk factors for complications in spinal osteotomy for AS patients were extensively investigated in this study. Age; preoperative GK, LL, and SVA; correction of GK, LL, and SVA; 2-level PSO; and long fusion were identified as risk factors. Our findings were comparable to those of prior studies reporting complications in adult 
spinal deformity (ASD). In agreement with previous ASD studies, $, 911,25$ our study showed that increased age and number of instrumented levels were also significant predisposing factors. In contrast to the findings of Kothari et al., ${ }^{19}$ female sex was not associated with a higher risk for complications in the current study, which may be explained by the fact that the proportion of female patients was small in our study. Charosky et al. ${ }^{9}$ reported that fusion to the sacrum was one of the risk factors for overall complications in a multicenter study of 306 patients undergoing primary adult scoliosis surgery; however, no significant difference was observed in the complication rates between the patients who underwent sacral fusion and those who did not in the present study.

Although the findings of our study seem to be partially in line with the results of previous studies, our study provides a new and valuable contribution in 2 specific ways. 1) We evaluated the complications in detail and described the incidence of complications within the 1st postoperative year in a large case series of AS patients with thoracolumbar kyphosis undergoing spinal osteotomy, which provided more recent data about the complications compared to the previous study. ${ }^{39}$ 2) This is the first study to investigate the risk factors for complications after spinal osteotomy for the thoracolumbar kyphosis secondary to AS, which would be helpful for preoperative risk stratification and surgical decision-making. One limitation of this study is that the data were reviewed and analyzed retrospectively. Future prospective studies are required to establish a definite causal relationship between the risk factors and occurrence of complications.

\section{Conclusions}

An overall incidence of complications (occurring within 1 year after surgery) of $13.7 \%$, with a $2.6 \%$ rate of major complications, in a series of AS patients with thoracolumbar kyphosis undergoing spinal osteotomy (PSO and SPOs) was documented in this study. Age; preoperative GK, LL, and SVA; correction of GK, LL, and SVA; 2-level PSO; and number of instrumented vertebrae were significant risk factors. Therefore, spine surgeons should be aware of the potential risk for the development of complications caused by large correction with long fusion in older AS patients with severe GK.

\section{Acknowledgments}

Bang-ping Qian received funding from the National Natural Science Foundation of China (81372009) and Jiangsu Provincial Medical Talent Program. Yong Qiu received funding from the Jiangsu Provincial Key Medical Center.

\section{References}

1. Adams JC: Technique, dangers and safeguards in osteotomy of the spine. J Bone Joint Surg Br 34-B:226-232, 1952

2. Arun R, Dabke HV, Mehdian H: Comparison of three types of lumbar osteotomy for ankylosing spondylitis: a case series and evolution of a safe technique for instrumented reduction. Eur Spine J 20:2252-2260, 2011

3. Auerbach JD, Lenke LG, Bridwell KH, Sehn JK, Milby $\mathrm{AH}$, Bumpass D, et al: Major complications and comparison between 3-column osteotomy techniques in 105 consecu- tive spinal deformity procedures. Spine (Phila Pa 1976) 37:1198-1210, 2012

4. Berdal G, Halvorsen S, van der Heijde D, Mowe M, Dagfinrud $\mathrm{H}$ : Restrictive pulmonary function is more prevalent in patients with ankylosing spondylitis than in matched population controls and is associated with impaired spinal mobility: a comparative study. Arthritis Res Ther 14:R19, 2012

5. Braun J, Sieper J: Ankylosing spondylitis. Lancet 369:13791390, 2007

6. Buchowski JM, Bridwell KH, Lenke LG, Kuhns CA, Lehman RA Jr, Kim YJ, et al: Neurologic complications of lumbar pedicle subtraction osteotomy: a 10-year assessment. Spine (Phila Pa 1976) 32:2245-2252, 2007

7. Castillo-Ortiz JD, Ramiro S, Landewé R, van der Heijde D, Dougados M, van den Bosch F, et al: Work outcome in patients with ankylosing spondylitis: results from a 12-year followup of an international study. Arthritis Care Res (Hoboken) 68:544-552, 2016

8. Chang KW, Chen YY, Lin CC, Hsu HL, Pai KC: Closing wedge osteotomy versus opening wedge osteotomy in ankylosing spondylitis with thoracolumbar kyphotic deformity. Spine (Phila Pa 1976) 30:1584-1593, 2005

9. Charosky S, Guigui P, Blamoutier A, Roussouly P, Chopin $\mathrm{D}$ : Complications and risk factors of primary adult scoliosis surgery: a multicenter study of 306 patients. Spine (Phila Pa 1976) 37:693-700, 2012

10. Cho KJ, Bridwell KH, Lenke LG, Berra A, Baldus C: Comparison of Smith-Petersen versus pedicle subtraction osteotomy for the correction of fixed sagittal imbalance. Spine (Phila Pa 1976) 30:2030-2038, 2005

11. Daubs MD, Lenke LG, Cheh G, Stobbs G, Bridwell KH: Adult spinal deformity surgery: complications and outcomes in patients over age 60. Spine (Phila Pa 1976) 32:22382244, 2007

12. Debarge R, Demey G, Roussouly P: Radiological analysis of ankylosing spondylitis patients with severe kyphosis before and after pedicle subtraction osteotomy. Eur Spine J 19:6570,2010

13. Ha Y, Maruo K, Racine L, Schairer WW, Hu SS, Deviren V, et al: Proximal junctional kyphosis and clinical outcomes in adult spinal deformity surgery with fusion from the thoracic spine to the sacrum: a comparison of proximal and distal upper instrumented vertebrae. J Neurosurg Spine 19:360-369, 2013

14. Hehne HJ, Zielke K, Böhm H: Polysegmental lumbar osteotomies and transpedicled fixation for correction of longcurved kyphotic deformities in ankylosing spondylitis. Report on 177 cases. Clin Orthop Relat Res (258):49-55, 1990

15. Hua WB, Zhang YK, Gao Y, Liu XZ, Yang SH, Wu XH, et al: Analysis of sagittal parameters in patients undergoing one- or two-level closing wedge osteotomy for correcting thoracolumbar kyphosis secondary to ankylosing spondylitis. Spine (Phila Pa 1976) 42:E848-E854, 2017

16. Kawahara N, Tomita K, Baba H, Kobayashi T, Fujita T, Murakami H: Closing-opening wedge osteotomy to correct angular kyphotic deformity by a single posterior approach. Spine (Phila Pa 1976) 26:391-402, 2001

17. Kim HJ, Iyer S, Zebala LP, Kelly MP, Sciubba D, Protopsaltis TS, et al: Perioperative neurologic complications in adult spinal deformity surgery: incidence and risk factors in 564 patients. Spine (Phila Pa 1976) 42:420-427, 2017

18. Kim KT, Lee SH, Suk KS, Lee JH, Im YJ: Spinal pseudarthrosis in advanced ankylosing spondylitis with sagittal plane deformity: clinical characteristics and outcome analysis. Spine (Phila Pa 1976) 32:1641-1647, 2007

19. Kothari P, Lee NJ, Leven DM, Lakomkin N, Shin JI, Skovrlj B, et al: Impact of gender on 30-day complications after adult spinal deformity surgery. Spine (Phila Pa 1976) 41:11331138,2016 
20. Labrom RD, Hoskins M, Reilly CW, Tredwell SJ, Wong PK: Clinical usefulness of somatosensory evoked potentials for detection of brachial plexopathy secondary to malpositioning in scoliosis surgery. Spine (Phila Pa 1976) 30:2089-2093, 2005

21. Lichtblau PO, Wilson PD: Possible mechanism of aortic rupture in orthopaedic correction of rheumatoid spondylitis. J Bone Joint Surg Am 38-A:123-127, 1956

22. Liu C, Zheng G, Zhang Y, Tang X, Song K, Fu J, et al: The radiologic, clinical results and digestive function improvement in patients with ankylosing spondylitis kyphosis after pedicle subtraction osteotomy. Spine J 15:1988-1993, 2015

23. Liu H, Yang C, Zheng Z, Ding W, Wang J, Wang H, et al: Comparison of Smith-Petersen osteotomy and pedicle subtraction osteotomy for the correction of thoracolumbar kyphotic deformity in ankylosing spondylitis: a systematic review and meta-analysis. Spine (Phila Pa 1976) 40:570-579, 2015

24. Park YS, Kim HS, Baek SW: Spinal osteotomy in ankylosing spondylitis: radiological, clinical, and psychological results. Spine J 14:1921-1927, 2014

25. Phan K, Kim JS, Somani S, Di Capua J, Kim R, Shin J, et al: Impact of age on 30-day complications after adult deformity surgery. Spine (Phila Pa 1976) 43:120-126, 2018

26. Qian BP, Jiang J, Qiu Y, Wang B, Yu Y, Zhu ZZ: Radiographical predictors for postoperative sagittal imbalance in patients with thoracolumbar kyphosis secondary to ankylosing spondylitis after lumbar pedicle subtraction osteotomy. Spine (Phila Pa 1976) 38:E1669-E1675, 2013

27. Qian BP, Mao SH, Jiang J, Wang B, Qiu Y: Mechanisms, predisposing factors and prognosis of intra-operative vertebral subluxation during pedicle subtraction osteotomy in surgical correction of thoracolumbar kyphosis secondary to ankylosing spondylitis. Spine (Phila Pa 1976) 42:E983-E990, 2017

28. Qian BP, Qiu Y, Wang B, Sun X, Zhu ZZ, Jiang J, et al: Pedicle subtraction osteotomy through pseudarthrosis to correct thoracolumbar kyphotic deformity in advanced ankylosing spondylitis. Eur Spine J 21:711-718, 2012

29. Schwartz DM, Drummond DS, Hahn M, Ecker ML, Dormans JP: Prevention of positional brachial plexopathy during surgical correction of scoliosis. J Spinal Disord 13:178-182, 2000

30. Scudese VA, Calabro JJ: Vertebral wedge osteotomy. Correction of rheumatoid (ankylosing) spondylitis. JAMA 186:627631, 1963

31. Smith-Petersen MN, Larson CB, Aufranc OE: Osteotomy of the spine for correction of flexion deformity in rheumatoid arthritis. J Bone Joint Surg Am 27:1-11, 1945

32. Uribe JS, Kolla J, Omar H, Dakwar E, Abel N, Mangar D, et al: Brachial plexus injury following spinal surgery. J Neurosurg Spine 13:552-558, 2010

33. van der Heijde D, Breban M, Halter D, DiVittorio G, Bratt J, Cantini F, et al: Maintenance of improvement in spinal mobility, physical function and quality of life in patients with ankylosing spondylitis after 5 years in a clinical trial of adalimumab. Rheumatology (Oxford) 54:1210-1219, 2015

34. van der Linden S, Valkenburg HA, Cats A: Evaluation of diagnostic criteria for ankylosing spondylitis. A proposal for modification of the New York criteria. Arthritis Rheum 27:361-368, 1984

35. van Genderen S, Plasqui G, Landewé R, Lacaille D, Arends $S$, van Gaalen F, et al: Social role participation in patients with ankylosing spondylitis: a cross-sectional comparison with population controls. Arthritis Care Res (Hoboken) 68:1899-1905, 2016

36. van Royen BJ, de Kleuver M, Slot GH: Polysegmental lumbar posterior wedge osteotomies for correction of kyphosis in ankylosing spondylitis. Eur Spine J 7:104-110, 1998

37. Wang Y, Zhang Y, Mao K, Zhang X, Wang Z, Zheng G, et al: Transpedicular bivertebrae wedge osteotomy and discectomy in lumbar spine for severe ankylosing spondylitis. J Spinal Disord Tech 23:186-191, 2010

38. Weatherley C, Jaffray D, Terry A: Vascular complications associated with osteotomy in ankylosing spondylitis: a report of two cases. Spine (Phila Pa 1976) 13:43-46, 1988

39. Willems KF, Slot GH, Anderson PG, Pavlov PW, de Kleuver M: Spinal osteotomy in patients with ankylosing spondylitis: complications during first postoperative year. Spine (Phila Pa 1976) 30:101-107, 2005

40. Wilson MJ, Turkell JH: Multiple spinal wedge osteotomy; its use in a case of Marie-Strumpell spondylitis. Am J Surg 77:777-782, 1949

\section{Disclosures}

The authors report no conflict of interest concerning the materials or methods used in this study or the findings specified in this paper.

\section{Author Contributions}

Conception and design: Qian, Huang, Qiu. Acquisition of data: Qian, Huang, Wang, Yu, Zhu, Mao, Jiang. Analysis and interpretation of data: Huang. Drafting the article: Huang. Critically revising the article: Qian, Qiu. Reviewed submitted version of manuscript: all authors. Approved the final version of the manuscript on behalf of all authors: Qian. Statistical analysis: Huang. Study supervision: Qian, Qiu.

\section{Correspondence}

Bang-ping Qian: Drum Tower Hospital of Nanjing University, Nanjing, China. qianbangping@163.com. 